\title{
Self-care, education, and awareness of the patient with temporomandibular disorder: a systematic review
}

\author{
Autocuidado, educação e conscientização do paciente com disfunção temporomandibular: \\ revisão sistemática
}

Giovanna Pimentel ${ }^{1}$, Daniel Bonotto², Priscila Brenner Hilgenberg-Sydney²

DOI 10.5935/2595-0118.20180050

\section{ABSTRACT}

BACKGROUND AND OBJECTIVES: Temporomandibular disorder consists of a variety of conditions associated with pain and dysfunction of the temporomandibular joint, masticatory muscles and associated structures. Self-care clinical protocols are commonly used as initial therapy for temporomandibular disorder patients after diagnosis as a conservative and non-invasive approach. This review aimed to study the self-care techniques in the literature and its efficacy.

CONTENTS: This was a systematic review of the literature, with a survey in the databases Science Direct and Pubmed, in addition to the gray literature, Google Scholar. The following descriptors were used: "self-care", "temporomandibular dysfunction" and "counseling". Articles in English and Portuguese published between 2010 and 2018 were included. Twenty-one articles were selected based on a series of inclusion and exclusion criteria.

CONCLUSION: There are two main objectives in the treatment of temporomandibular disorder patients, the reduction of pain and improvement of function. It was concluded that self-care therapies are effective in achieving these goals, in addition to being low-tech and non-invasive. Patients who actively participate in their healing process present faster improvements, by altering their general perception of pain.

Keywords: Conservative treatment, Protocols, Temporomandibular joint disorders.

1. Universidade Federal do Paraná, Faculdade de Odontologia, Curitiba, PR, Brasil.

2. Universidade Federal do Paraná, Faculdade de Odontologia, Departamento de Odontologia Restauradora, Setor de Ciências da Saúde, Curitiba, PR, Brasil.

Submitted in February 20, 2018

Accepted for publication on August 01, 2018

Conflict of interests: none - Sponsoring sources: none.

Correspondence to:

Av. Prefeito Lothário Meissner, 632 - Jardim Botânico

80210-170 Curitiba, PR, Brasil.

E-mail: giovanna.b.pimentel@gmail.com

(C) Sociedade Brasileira para o Estudo da Dor

\section{RESUMO}

JUSTIFICATIVA E OBJETIVOS: Disfunção temporomandibular consiste em uma variedade de condiçóes associadas com dor e disfunção da articulação temporomandibular, músculos da mastigação e estruturas associadas. Os protocolos clínicos de autocuidado são comumente usados como terapia inicial do paciente com disfunção temporomandibular, após o diagnóstico, como uma abordagem conservadora e não invasiva. $\mathrm{O}$ objetivo deste estudo foi estudar as técnicas de autocuidado presentes na literatura e sua eficácia.

CONTEÚDO: Foi realizada uma revisão sistemática da literatura, com um levantamento nas bases de dados Science Direct e Pubmed, além da literatura cinzenta, Google Acadêmico. Os seguintes descritores foram utilizados: "autocuidado", "disfunção temporomandibular" e "aconselhamento". Artigos em inglês e português, publicados entre 2010 e 2018 , foram incluídos. Vinte e um artigos foram selecionados com base em uma série de critérios de inclusão e exclusão.

CONCLUSÁO: Há dois objetivos principais no tratamento do paciente com disfunção temporomandibular, sendo a redução da dor e a melhora da funçáo. Concluiu-se que terapias de autocuidado são efetivas em atingir estes objetivos, além de não-invasivas e de baixo custo tecnológico. Pacientes que participam ativamente no próprio processo de cura apresentam melhorias mais rapidamente, alterando sua percepção geral da dor.

Descritores: Protocolos, Transtornos da articulação temporomandibular, Tratamento conservador.

\section{INTRODUCTION}

Self-management clinical protocols are commonly used as initial treatment for patients with temporomandibular disorders (TMD), after adequate diagnosis, as a conservative and non-invasive approach ${ }^{1}$. They should be simple enough to allow the patient's control over the execution and enable healing and/or prevention of more injuries to the musculoskeletal system. The main objectives of any treatment for chronic pain consist in reducing pain and improving quality of life ${ }^{2}$.

The variety of self-care techniques include education; jaw exercises (such as stretching and relaxation); massage; thermal therapy; dietary advice and nutrition; and parafunctional behavior identification, monitoring, and avoidance ${ }^{1}$.

It is important for the professional to acknowledge such techniques because the adoption of a self-care protocol may be sufficient therapy for the adaptive and motivated patients, or it may 
be an essential part of a more complex and multidisciplinary treatment plan ${ }^{3}$.

The objectives of this present study were to systematically review the literature about the efficacy and applicability of self-management therapies to TMD patients, as well as orientations, education, and awareness of these patients, and to propose a clinical protocol.

\section{CONTENTS}

The included articles in this review were those concerning conservative and self-care therapies for the treatment of TMD patients. A period filter was applied to only select articles published between 2010 and 2018. There was also a filter for language and articles were accepted only in English and Portuguese.

Furthermore, the following exclusion criteria were applied: 1) Irreversible or more invasive treatments; 2) Pharmacotherapy; 3) Studies with children; and 4) Studies with patients with special needs.
Searches were performed in two databases: 1. Science Direct; 2. Pubmed; and the gray literature, Google Scholar. The last electronic database search was performed on February 27 2017.

The selected keywords were: I. Self-management, II. Temporomandibular disorders, and III. Counseling. The first search included only self-management (I); followed by temporomandibular disorders (II) alone. The searched combinations were: self-management and temporomandibular disorders (I and II); and self-management, temporomandibular disorders and counseling (I, II and III).

The elected search was the one that joined the keywords: self-management, temporomandibular disorders and counseling (I, II and III), with 209 results.

From the elected survey, these articles were pooled for a series of inclusion and exclusion steps, as shown in figure 1. The research presented many results not related specifically to the theme, so the first step aimed to reduce the total number of articles. First exclusion step consisted of reading the titles, and the unrelated

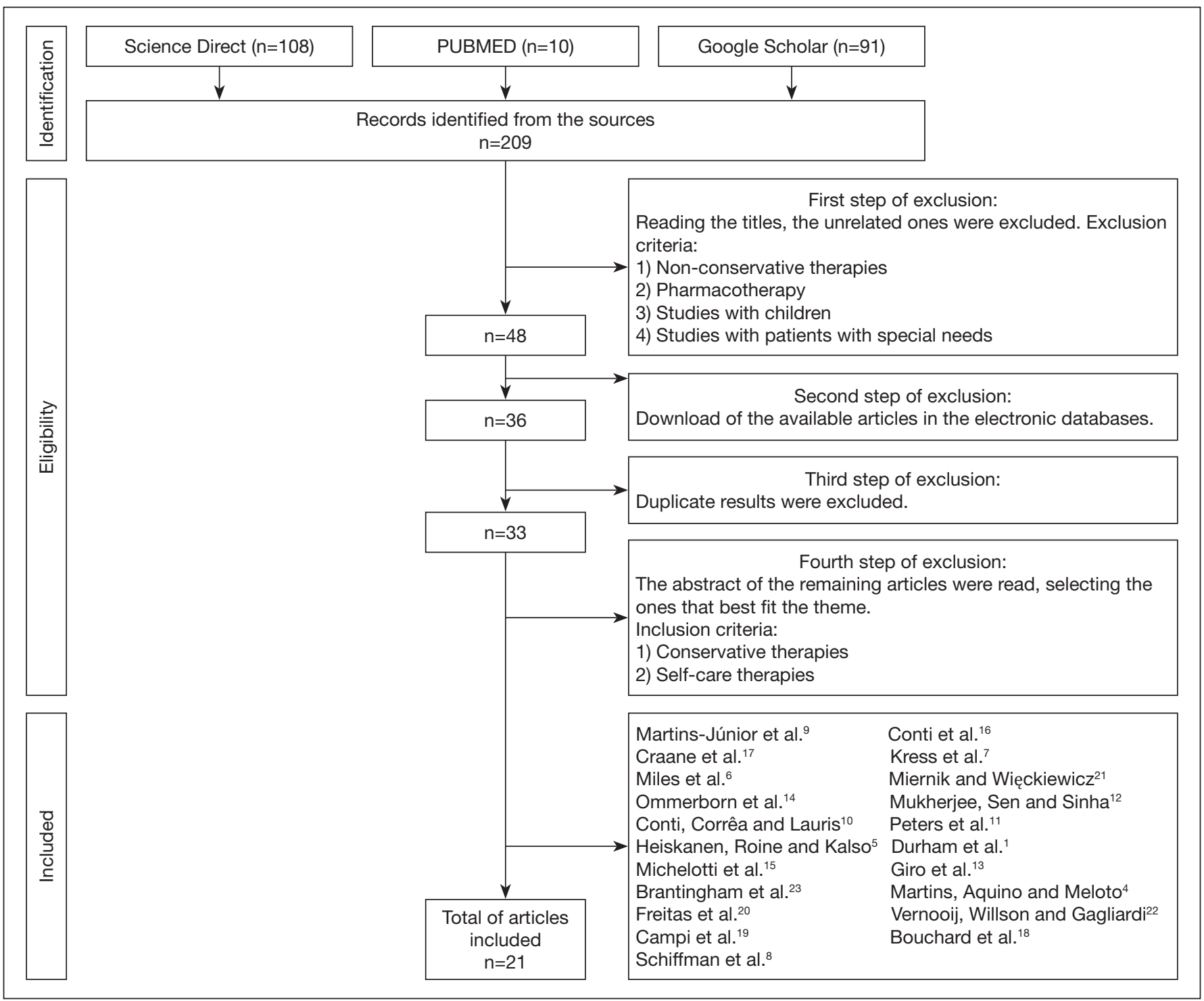

Figure 1. Flowchart of the selection of the articles. 
ones were excluded. The second step was the pdf download of the results, selecting only those that were available at the Federal University of Paraná database. The third step consisted of removing the duplicate articles from the three databases. As a fourth and final step, the abstracts of the 33 remaining articles were read, and those concerning conservative and self-care therapies were selected, reaching a total of 21 articles.

\section{DISCUSSION}

The scope of this systematic review was to synthesize the literature regarding conservative therapies and self-management guidelines, aiming at a biopsychosocial approach in the treatment of TMD patients.

TMD treatment is not standardized due to the different etiologies and distinct structures that might be affected ${ }^{4}$. However, the indication of self-care protocols, in addition to education and awareness of the patient's own dysfunction, are powerful tools to relieve symptoms. Self-care new habits may be all that is required for those patients that are adaptive and self-motivated, and/or it also may be part of a more complex multi-modal treatment plan ${ }^{1}$. According to Heiskanen, Roine e Kalso ${ }^{5}$ health-related quality of life of chronic pain patients improved during a multi-disciplinary treatment, whereas the factors explaining poor response were not treatment-related, such as occupation and degree of education.

The main factors that might influence the outcome of a selfcare program are self-efficacy, depression, pain catastrophizing and physical activity ${ }^{6}$. These programs rely on a therapeutic alliance between clinician and patient, which requires patient cooperation and clinician commitment, such as monitoring and constant evaluation of the dysfunction's progression, in order to readapt the therapeutic alternatives ${ }^{1}$. Other important measures include chronic pain being recognized as a disease and the adoption of a patient-centered and personalized treatment approach ${ }^{7}$. Schiffman et al. ${ }^{8}$ compared four therapeutic approaches for the temporomandibular joint closed lock (two of them non-invasive, and the other two invasives), and found that there was no clinically significant difference. Therefore, educating and providing the patient with self-care techniques is the proper strategy for initial care. It empowers the patient to know that they have the innate ability to heal - and the clinician's engagement, training them to do so, is a great facilitating factor ${ }^{1}$.

The conservative therapy for TMD success rate can reach values above 90 percent, so there is no need for invasive, irreversible and high-tech treatments for most of the patients ${ }^{9}$. Conti, Corrêa and Lauris ${ }^{10}$ found that all management strategies were effective in reducing the reported pain intensity, but patients improved faster when wearing occlusal devices associated with counseling and behavior changes. It is unlikely that self-care acts as a unique therapeutic strategy, however, this kind of self-regulatory behavior influences the overall pain perception ${ }^{1}$.

The highest evidence of benefit in the treatment of a TMD patient points out to psychological interventions, more specifically cognitive behavioral therapy - especially when associated with biofeedback, reducing pain intensity, activity interference, and depression levels ${ }^{11}$.

Orientations from the revised literature are shown in table 1. Based on that, a proposed self-management clinical protocol is shown in table 2 . The intention is to distribute these orientations to TMD patients.

Table 1. Orientations for the clinician, regarding conservative therapies for the treatment of the temporomandibular disorders patient

\begin{tabular}{lll}
\hline Therapy & Authors & Conclusion \\
\hline Education & Durham et al. ${ }^{1}$ & Diagnosis and "optimistic counseling" (reassurance that TMD is typically benign and self-limiting \\
& & $\begin{array}{l}\text { in the clear majority of cases). Education should also include TMD's biopsychosocial etiology; cau- } \\
\text { tions against invasive and irreversible treatments; sleep practices; sensible and time-limited use of } \\
\text { analgesia; avoidance of OTC splints bought without consultation with the dentist; caffeine usage; } \\
\text { anatomy and usual function of TMJ complex and associated musculature. }\end{array}$
\end{tabular}

Michelotti et al. ${ }^{15}$ Patients that receive extensive information and considerable patient-doctor interaction present faster improvement. Therefore, the psychophysiological mechanisms associated with education and reassurance reveal positive effects. The improvement is mediated, however, by each patient's coping skills, mood and emotional state.

Conti et al. ${ }^{16} \quad$ Education is slightly more effective than only an occlusal appliance in treating spontaneous muscle pain.

Freitas et al. ${ }^{20} \quad$ Treatment modalities should include counseling and education for self-care and self-regulation, such as an explanation concerning the role of pain, possible etiological factors of the patient's TMD, the relationship between chronic pain and psychosocial distress, and its benign character. A list of recommendations can be given to patients:

- Encouragement of patients to rest their masticatory muscles;

- Observation and reduction in parafunctional habits;

- Avoidance of excessive mandibular movements;

- Maintenance of soft diet and recommendation to chew carefully;

- Performance of simultaneous bilateral mastication;

- Improvement of posture and sleep onset.

However, education should be associated with posture training and physical therapy programmes, since counseling and self-management-based therapies provide better results when they are not used alone. Also, although it represents a conservative low-cost and beneficial treatment for the relief of signs and symptoms by improving psychological domains and potentially reducing harmful behaviors, the evidence remains unclear due to the reduced number of controlled and randomized well-designed clinical trials. 
Table 1. Orientations for the clinician, regarding conservative therapies for the treatment of the temporomandibular disorders patient continuation

\begin{tabular}{lll}
\hline Therapy & Authors & Conclusion \\
\hline Education & $\begin{array}{l}\text { Miernik and } \\
\text { Więckiewicz }{ }^{21}\end{array}$ & $\begin{array}{l}\text { As the natural course of the closed lock is self-limiting, some authors recommend just education and } \\
\text { counseling. It is important to explain the mechanism of disc displacement and the negative effects } \\
\text { of parafunctions on the stomatognathic system, especially the TMJ. }\end{array}$ \\
& $\begin{array}{l}\text { Vernooij, Willson } \\
\text { Single or multifaceted educational interventions may reinforce general information about the condi- }\end{array}$
\end{tabular}
and Gagliardi22 tion and lifestyle advice and contribute to positive outcomes. Information and evidence about the condition, prognosis, what to expect, and its management. Information and advice on how to undertake generic activities such as hygiene, dressing, preparing meals, transportation. Information and guidance on lifestyle behaviors that support disease management.

Craane et al. ${ }^{17} \quad$ The study showed that improvement was purely based on the education of the patients, which includes informing and explaining the presumed etiology, the good prognosis of this benign disorder and reassuring the patient regarding this problem.

Self-exercise

Durham et al. Jaw (muscle) exercises, relaxation and posture training. Can be implemented by the clinician or by referral to other health care professions, such as physical or occupational therapists.

Craane et al. ${ }^{17} \quad$ Exhibits significant improvement over time for pain and impairment. However, there is no evidence of the clinically important benefit of a single physical therapeutic modality, while combinations of physical therapeutic modalities seem to be more effective than a single one.

Bouchard et al. ${ }^{18}$ For the treatment of non-reducing discs, institute a home exercise program performed for jaw muscle and range of motion.

Campi et al. ${ }^{19} \quad$ Stretching, stabilization, coordination and mobilization exercises. Although these treatments are effective to decrease pain and improve dysfunction associated with TMD, there is still a lack of studies defining effectiveness parameters.

Thermal modalities Durham et al. ${ }^{1} \quad$ Use of heat and /or ice to areas of pain.

Conti, Corrêa For painful temporomandibular joint clicking, hot thermotherapy.

and Lauris ${ }^{10}$

de Freitas et al. ${ }^{20}$ Apply heat or cold to the most painful masticatory areas.

Miernik and

Więckiewicz ${ }^{21}$

For the closed lock, the recommended self-care protocol might include thermotherapy (cold or warm packs) in the initial period of locking.

Giro et al..$^{13}$

Thermotherapy to promote pain relief, improve muscle tone, and relax mandibular muscles. Patients should be advised to place moist heat pads on the painful muscle for 15 minutes, 3 times per day.

Diet and nutrition Durham et al.

Clinicians should implement a "pain-free diet", as opposed to a "soft diet", for a two-week period. After that, a new review determines whether the individual advances as tolerated to firmer and chewier consistency foods.

Schiffman et al. ${ }^{8} \quad$ To the patient minimally inconvenienced by diet, should be recommended a regular diet that, at worst, avoids tough or hard foods.

Ommerborn Diet counseling for the patient with bruxism.

et al. ${ }^{14}$

Mukherjee, Sen For the management of orofacial pain, a successful home care program should emphasize a soft and Sinha ${ }^{12}$ diet. Some patients find eating mild food helpful.

Miernik and Więckiewicz ${ }^{21}$

For the closed lock, the recommended self-care protocol might include soft food diet in the initial period of locking.

Martins et al. ${ }^{4} \quad$ Avoid foods of thick consistency.

de Freitas et al. ${ }^{20}$ Maintenance of soft diet and recommendation to chew carefully.

Craane et al. ${ }^{17} \quad$ In their study, patients were advised to use a soft diet and chew bilaterally

Self-massage $\quad$ Durham et al. ${ }^{1} \quad$ Massage is limited to the anatomic location of the painful or tense affected masticatory muscles. The most easily accessible to palpation are masseter and temporalis.

Giro et al. ${ }^{13} \quad$ Self-massage promotes the improvement of local blood circulation and relieves pain and muscle tension. Patients can be instructed to bilaterally massage the masseter and temporal muscles 3 times per day with circular movements performed using the index, middle, and ring fingers. It was concluded that the improvement of blood flow in the masticatory muscles and decreased muscle tension provided by massages followed by exercises and hot pads can reduce pain, which also contributes to improvement in mandibular function.

Conti et al. ${ }^{16} \quad$ Instruct the patients to massage painful areas.

Brantingham Considered soft tissue procedures, such as trigger point therapy, transverse friction massage and et al. ${ }^{23} \quad$ therapeutic massage. A typical relaxing massage is focused on reducing muscular tension and improving circulation. 
Table 1. Orientations for the clinician, regarding conservative therapies for the treatment of the temporomandibular disorders patient continuation

\begin{tabular}{lll}
\hline Therapy & Authors & Conclusion \\
\hline $\begin{array}{l}\text { Parafunctional be- } \\
\text { havior monitoring }\end{array}$ & Durham et al. ${ }^{1}$ & $\begin{array}{l}\text { Orient the patient to identify, monitor, and avoid any parafunctional behavior that exacerbate their } \\
\text { pain. }\end{array}$ \\
$\begin{array}{l}\text { and avoidance }\end{array}$ &
\end{tabular}

Mukherjee, Sen A reduction in stress/tension-related parafunctional activity can lead to immediate less pain reported and Sinha ${ }^{12}$ by patients. A successful home care program includes parafunctional habit modification.

Miernik and It is important to explain the mechanism of disc displacement and the negative effects of parafuncWięckiewicz ${ }^{21}$ tions on the stomatognathic system, especially the TMJ.

Martins et al. ${ }^{4} \quad$ Their study revealed an improvement in the symptomology, which included modifications in parafunctional activities, greater awareness of the patient and the cognitive placebo effect. Counseling should include guidance on reducing parafunctional mandibular activities.

Giro et al. ${ }^{13} \quad$ Parafunctional habits are involved in the development and maintenance of the signs and symptoms of TMD. Behavioral therapies may help relieve musculoskeletal pain and restore mandibular function by reducing inflammation, relieving muscle tension, and improving psychological health. Counseling and self-care approaches include guidance in reducing parafunctional jaw activities.

de Freitas et al. ${ }^{20} \quad$ A TMD self-management program should orient the patient towards becoming aware of parafunctional habits, such as teeth clenching. Patient must be able to monitor and reduce muscle parafunction in the head and neck region.

Conti et al. ${ }^{16} \quad$ In their study, the improvement in pain reported after a 3-month period reflected the importance of behavioral alterations and the avoidance of deleterious and parafunctional habits in the facial pain of masticatory origin.

Campi et al. ${ }^{19} \quad$ A self-care program should include habit reversion techniques and correct jaw use.

Table 2. Self-management clinical protocol for the patient, including techniques and education with the purpose of awareness

\begin{tabular}{|c|c|}
\hline \multicolumn{2}{|c|}{ Self-management clinical protocol } \\
\hline $\begin{array}{l}\text { TMD definition and } \\
\text { etiology }\end{array}$ & $\begin{array}{l}\text { Temporomandibular disorder (TMD) refers to a group of masticatory system changes characterized by pain in the } \\
\text { temporomandibular joint (TMJ) and/or masticatory muscles, joint sounds, joint movement shifts or limitations. The } \\
\text { etiology of TMDs can be quite varied, and known causes include developmental conditions, trauma, infection, and } \\
\text { autoimmune conditions. However, the etiology most frequently seen in the clinic is at best speculative, and factors } \\
\text { that are frequently held as responsible for pain and dysfunction comprise grinding, clenching and stress. }\end{array}$ \\
\hline $\begin{array}{l}\text { "Optimistic counse- } \\
\text { ling" }\end{array}$ & $\begin{array}{l}\text { TMD is typically benign and self-limiting in the vast majority of cases. It is important to emphasize the good prognosis } \\
\text { of this benign disorder. Patients that receive extensive information and considerable patient-doctor interaction pre- } \\
\text { sent faster improvement. }\end{array}$ \\
\hline $\begin{array}{l}\text { Rest of masticatory } \\
\text { muscles }\end{array}$ & $\begin{array}{l}\text { Avoid excessive mandibular movements, such as chewing gums. When your jaw is at rest, your teeth should never } \\
\text { touch - the teeth only touch during chewing and swallowing. The jaw should be kept in the postural position, with the } \\
\text { teeth separated, avoiding an involuntary muscular contraction. To learn the position, repeatedly pronounce the letter } \\
\text { "N" and hold the tongue in this position behind the upper incisor teeth, with the lips in slight contact. Avoid leaning on } \\
\text { your jaw at rest. Limit your maximum buccal opening, especially when yawning or singing. }\end{array}$ \\
\hline $\begin{array}{l}\text { Soft diet/Bilateral } \\
\text { mastication }\end{array}$ & $\begin{array}{l}\text { Avoid tough, hard and thick consistency food. Try to eat soft food slowly, in small pieces. Some patients find eating } \\
\text { mild food helpful. Chew carefully and bilaterally, in order not to overload the TMJ. }\end{array}$ \\
\hline $\begin{array}{l}\text { Observation and re- } \\
\text { duction in parafunc- } \\
\text { tional habits }\end{array}$ & $\begin{array}{l}\text { Parafunctional habits exacerbate pain. They are involved in the development and maintenance of the signs and symp- } \\
\text { toms of TMD. Therefore, it is important to identify, monitor and avoid this type of habits. Avoid clenching and/or grind- } \\
\text { ing your teeth. Avoid pen (objects in general) and nails biting. Use some type of reminder to notice any parafunctions } \\
\text { and try to turn them into a non-jaw-related habit. Patient must be able to monitor and reduce muscle parafunction in } \\
\text { the head and neck region. }\end{array}$ \\
\hline $\begin{array}{l}\text { Improvement of } \\
\text { posture }\end{array}$ & $\begin{array}{l}\text { This is part of a specific physical self-regulation strategy which helps in the management of pain complaints. It invol- } \\
\text { ves posture training with a physical therapist, awareness training to improve symmetric head and neck postures and } \\
\text { training in diaphragmatic breathing. }\end{array}$ \\
\hline Improvement of sleep & $\begin{array}{l}\text { This is also part of a specific physical self-regulation strategy which helps in the management of pain complaints. It } \\
\text { involves instructions for improving sleep onset, position-oriented relaxation training and positioning the pillow sup- } \\
\text { porting the head and neck during sleep. }\end{array}$ \\
\hline Use of heat & $\begin{array}{l}\text { Apply hot packs to areas of pain, for } 15 \text { minutes } 3 \text { times per day. Thermotherapy promotes pain relief, improves mus- } \\
\text { cle tone and relaxes mandibular muscles. }\end{array}$ \\
\hline Self-massage & $\begin{array}{l}\text { Bilaterally massage the masseter and temporal muscles } 3 \text { times per day with circular movements performed using the } \\
\text { index, middle, and ring fingers. Self-massage promotes the improvement of local blood circulation and relieves pain } \\
\text { and muscle tension, which also contributes to the improvement in mandibular function. }\end{array}$ \\
\hline
\end{tabular}


Table 2. Self-management clinical protocol for the patient, including techniques and education with the purpose of awareness- continuation

\begin{tabular}{|c|c|}
\hline \multicolumn{2}{|c|}{ Self-management clinical protocol } \\
\hline $\begin{array}{l}\text { Jaw muscles exerci- } \\
\text { ses, relaxation } \\
\text { and posture training }\end{array}$ & $\begin{array}{l}\text { The therapeutic self-exercise consists in the prescription of muscular contractions and body movements in order to } \\
\text { improve general function and help satisfy the demands of daily life. } \\
\text { - Relaxation exercises: Movements of opening, laterality, protrusion and closing resistance (with the fist as support, } \\
\text { for example). } \\
\text { - Relaxation exercises with diaphragmatic breathing: Exhale completely with one hand resting on the chest and } \\
\text { the other on the abdomen, training to become aware of the mechanism of breathing only by the position and hand } \\
\text { movement. Diaphragmatic breathing should be performed for } 5 \text { minutes every day, every } 2 \text { hours. However, use this } \\
\text { coordinated breathing the most frequent possible throughout the day. } \\
\text { - Stretching exercises: Open your mouth slowly until you experience an initial sensation of pain. Open a little more } \\
\text { with slight pressure, positioning the thumb in the upper arch, approximately in the region of premolars, and the index } \\
\text { finger in the lower arch, also in the region of the premolars. The technique should be performed every day, every } 2 \\
\text { hours, keeping the elongated jaw in position for one minute, six times in a row. } \\
\text { - Coordination exercises: Consist of repeated opening, laterality, protrusion and mandibular retrusion movements. } \\
\text { They must be performed slowly and coordinated, in front of the mirror, } 3 \text { times per day. } \\
\text { - Mobilization exercises: Perform mandibular laterality movements to recapture the disc, if possible. Then perform } \\
\text { gentle protrusion and retrusion movements by holding some small object between the teeth. }\end{array}$ \\
\hline
\end{tabular}

\section{DIFFICULTIES}

There is a recognized difficulty in the establishment of a reference standard clinical protocol, or some type of guidelines for specific interventions, due to a lack of evidence of the efficacy of one treatment over another ${ }^{1}$ and also because there are a great variety of methods used in clinical trials.

Moreover, it is known that having a confirmed diagnosis is a necessary step towards effective clinical management, which is particularly difficult for TMD's, due to the multifactorial etiology of the TMD ${ }^{11}$. Several patients seek treatment for symptoms of diverse origins, or comorbidities, emphasizing the importance of differential diagnosis ${ }^{9}$. Orofacial pain management can be immensely challenging, so the clinician must be well aware of the variety of etiological factors and characteristics of these conditions ${ }^{12}$.

Another barrier is the impact of a wide range of demographic, clinical, psychological and social factors in the treatment outcome $^{6}$. Parafunctional habits, neuromuscular and psychosocial factors are involved in the development and maintenance of TMD's signs and symptoms. Hence treatments that take into account only biomedical factors are often insufficient to promote long-term improvement ${ }^{13}$.

\section{CONCLUSION}

There are two main objectives established for the treatment of the TMD patient: the control of pain severity and improvement of function. Current literature indicates that non-invasive and conservative therapies, with a good level of scientific evidence, are effective and more prudent.

Patients present better results when the professional is willing to inform them completely about their condition. This contributes to reducing the fear, depression and anxiety that are characteristic of the patient with chronic pain. It becomes the clinician responsibility to study the self-management therapies in the literature, in order to guide the patient in his individuality and in the particularities of his clinical case, enabling him in the light of his own dysfunction.

\section{REFERENCES}

1. Durham J, Al-Baghdadi M, Baad-Hansen L, Breckons M, Goulet JP, Lobbezoo F, et al. Self-management programmes in temporomandibular disorders: results from an international Delphi process. J Oral Rehabil. 2016;43(12):929-36.

2. De Laat A, Stappaerts K, Papy S. Counseling and physical therapy as treatment for myofascial pain of the masticatory system. J Orofac Pain. 2003;17(1):42-9.

3. Türp JC, Jokstad A, Motschall E, Schindler HJ, Windecker-Gétaz I, Ettlin DA. Is there a superiority of multimodal as opposed to simple therapy in patients with temporomandibular disorders? A qualitative systematic review of the literature. Clin Oral Implants Res. 2007;18(Suppl 3):138-50.

4. Martins AP, Aquino LM, Meloto CB, Barbosa CM. Counseling and oral splint for conservative treatment of temporomandibular dysfunction: preliminary study. Rev Odontol UNESP. 2016;45(4):207-13.

5. Heiskanen T, Roine RP, Kalso E. Multidisciplinary pain treatment - which patients do benefit? Scand J Pain. 2012;3(4):201-7.

6. Miles CL, Pincus T, Carnes D, Homer KE, Taylor SJ, Bremner SA, Rahman A, et al. Can we identify how programmes aimed at promoting self-management in musculoskeletal pain work and who benefits? A systematic review of sub-group analysis within RCTs. Eur J Pain. 2011;15(8):775-e1-11.

7. Kress HG, Aldington D, Alon E, Coaccioli S, Collett B, Coluzzi F, et al. A holistic approach to chronic pain management that involves all stakeholders: change is needed. Curr Med Res Opin. 2015;31(9):1743-54.

8. Schiffman EL, Velly AM, Look JO, Hodges JS, Swift JQ, Decker KL, et al. Effects of four treatment strategies for temporomandibular joint closed lock. Int J Oral Maxillofac Surg. 2014; $43(2): 217-26$.

9. Martins-Júnior RL, Palma AJ, Marquardt EJ, Gondin TM, Kerber Fde C. Temporomandibular disorders: a report of 124 patients. J Contemp Dent Pract. 2010;11(5):71-8.

10. Conti PC, Corrêa AS, Lauris JR, Stuginski-Barbosa J. Management of painful temporomandibular joint clicking with different intraoral devices and counseling: a controlled study. J Appl Oral Sci. 2015;23(5):529-35.

11. Peters S, Goldthorpe J, McElroy C, King E, Javidi H, Tickle M, et al. Managing chronic orofacial pain: A qualitative study of patients', doctors', and dentists' experiences. Br J Health Psychol. 2015;20(4):777-91.

12. Mukherjee $S$, Sen $S$, Sinha $S$. Orofacial pain: a critical appraisal in management. Indian J Pain. 2015;29(3):127-34.

13. Giro G, Policastro VB, Scavassin PM, Leite AR, Mendoza Marin DO, Gonçalves DA, et al. Mandibular kinesiographic pattern of women with chronic TMD after management with educational and self-care therapies: a double-blind, randomized clinical trial. J Prosthet Dent. 2016;116(5):749-55.

14. Ommerborn MA, Taghavi J, Singh P, Handschel J, Depprich RA, Raab WH. Therapies most frequently used for the management of bruxism by a sample of German dentists. J Prosthet Dent. 2011;105(3):194-202.

15. Michelotti A, Iodice G, Vollaro S, Steenks MH, Farella M. Evaluation of the shortterm effectiveness of education versus an occlusal splint for the treatment of myofascial pain of the jaw muscles. J Am Dent Assoc. 2012;143(1):47-53.

16. Conti PC, de Alencar EN, da Mota Corrêa AS, Lauris JR, Porporatti AL, Costa YM. Behavioural changes and occlusal splints are effective in the management of masticatory myofascial pain: a short-term evaluation. J Oral Rehabil. 2012;39(10):754-60.

17. Craane B, Dijkstra PU, Stappaerts K, De Laat A. One-year evaluation of the effect of physical therapy for masticatory muscle pain: a randomized controlled trial. Eur J Pain. 2012;16(5):737-47.

18. Bouchard C, Goulet JP, El-Ouazzani M, Turgeon AF. Temporomandibular lavage versus nonsurgical treatments for temporomandibular disorders: a systematic review and meta-analysis. J Oral Maxillofac Surg. 2017;75(7):1352-62. 
19. Campi LB, Camparis CM, Jordani PC, Gonçalves DA. Influence of biopsychosocial approaches and self-care to control chronic pain and temporomandibular disorders. Rev Dor. 2013;14(3):219-22.

20. de Freitas RF, Ferreira MÂ, Barbosa GA, Calderon PS. Counselling and self-management therapies for temporomandibular disorders: a systematic review. J Oral Rehabil. 2013;40(11):864-74.

21. Miernik AM, Więckiewicz W. The basic conservative treatment of temporomandibular joint anterior disc displacement without reduction--review. Adv Clin Exp Med.
2015;24(4):731-5.

22. Vernooij RW, Willson M, Gagliardi AR. Characterizing patient-oriented tools that could be packaged with guidelines to promote self-management and guideline adoption: a meta-review. Implement Sci. 2015;11:52.

23. Brantingham JW, Cassa TK, Bonnefin D, Pribicevic M, Robb A, Pollard H, et al. Manipulative and multimodal therapy for upper extremity and temporomandibular disorders: a systematic review. J Manipulative Physiol Ther. 2013;36(3):143-201. 